\title{
DOCTRINA
}

\section{ACCESO A HISTORIAS CLÍNICAS Y DEMÁS DATOS SANITARIOS POR PARTE DE FISCALES PENALES}

Diego Andrade Sosa* Valeria Escobar Suhr* *

\begin{abstract}
RESUMEN. En el presente artículo analizaremos si, a la luz del nuevo Código del Proceso Penal, vigente desde 2017, los Fiscales pueden tener acceso a datos sanitarios de personas. Para ello se hará un desarrollo relativo a la caracterización de este tipo de información desde la óptica de la protección del derecho a la intimidad y la tutela del secreto profesional.
\end{abstract}

PALABRAS CLAVE. Fiscales. Código de Proceso Penal. Derecho a la intimidad. Confidencialidad. Secreto profesional. Datos sanitarios. Historias clínicas.

ABSTRACT. Throughout this paper it is analyzed whether, according to the new Code of Criminal Procedure, in force since 2017, Prosecutors may have access to people's health data. For this purpose, the characterization of this type of information will be developed from the perspective of protecting the right to privacy and professional secrecy.

KEY WORDS. Public prosecutors-code of criminal procedure. Right to privacy. Confidentiality - Profesional secrecy. Health data-medical.

\section{INTRODUCCIÓN.}

La entrada en vigencia del denominado "Nuevo Código del Proceso Penal" implicó, además de la consagración de un sistema penal acusatorio, adversarial, oral y público, la atribución de determinadas facultades al Ministerio Público, en su carácter de titular de la acción penal.

* Doctor en Derecho y Ciencias Sociales (FD-UR). Ayudante (G1) de Derecho Civil (FCEA-UR). Aspirante a Profesor Adscripto de Derecho del Trabajo y de la Seguridad Social (FD-UR). Maestrando en Derecho del Trabajo y de la Seguridad Social (FD-UR). Correo electrónico: dandradesosa@gmail.com

**Doctora en Derecho y Ciencias Sociales (FD-UR). Asistente (G2) de Derecho Civil (FCEA-UR). Ayudante (G1) Derecho Privado IV y V (FD-UR). Maestrando en Derecho Comercial (FD-UR). Correo electrónico: vescobarsuhr@gmail.com 
A los efectos anteriormente señalados, el mentado Código, aprobado por la Ley N ${ }^{\circ} 19.293$ de 19/12/2014, coloca al fiscal en la situación de poder-deber respecto a la adopción de todas las medidas necesarias para el éxito de la investigación criminal y/o del procedimiento penal.

Particularmente el artículo 45 del aludido cuerpo normativo confiere una serie de atribuciones a los integrantes del Ministerio Público, dentro de las que resulta menester destacar a los efectos del presente trabajo las de "disponer la presencia en su despacho de todas aquellas personas que puedan aportar elementos útiles para la investigación, incluyendo el indagado, el denunciante, testigos y peritos"; así como "Solicitar, en forma fundada, a las instituciones públicas o privadas, toda información que sea necesaria en el marco de la investigación que se encuentre realizando y esté disponible en sus registros, siempre que la entrega no implique afectación de garantías o derechos fundamentales de las personas" (literales "b" y "k" del artículo de marras).

Nuestra labor profesional nos ha permitido tomar conocimiento de que en algunos centros asistenciales y sanitarios del país se han recibido solicitudes a proporcionar acceso a historias clínicas de usuarios de los mismos, provenientes de Fiscalías, en el marco de la instrucción de investigaciones criminales y al amparo de las potestades mencionadas utsupra. Asimismo, se ha advertido que diversos integrantes de los equipos asistenciales son convocados a los despachos fiscales para brindar su testimonio relativo al estado sanitario de un determinado paciente.

El objeto principal del presente trabajo será determinar si las atribuciones conferidas por el precitado cuerpo normativo son suficientes para que el Ministerio Público pueda requerir a instituciones públicas y privadas información sobre el estado sanitario de personas en general, y de sus historias clínicas en particular.

Para ello, comenzaremos con un análisis referente al rango de protección del que se dota a los datos sobre el estado de salud de una persona en el contexto del derecho a la intimidad.

En segundo término, haremos un desarrollo relativo a la vinculación entre el secreto profesional y la información sanitaria de una persona, en el marco de la relación médicopaciente.

En tercer lugar, expondremos a la regulación del acceso a historias clínicas en la normativa nacional.

En cuarto lugar, abordaremos cuales son las perspectivas de acceso a datos sanitarios personales con las que cuentan actualmente, a la luz de los textos positivos vigentes.

Finalmente expondremos las conclusiones a las que nuestro modesto análisis nos haya permitido arribar.

\section{LA PROTECCIÓN DE LOS DATOS SANITARIOS DE LA PERSONA.}

\subsection{Los datos sanitarios en el marco de la protección al derecho a la intimidad.}

BERRO y ADRIASOLA, citando una sentencia del Tribunal Constitucional Español, refieren que el derecho a la intimidad tiene por objeto "garantizar al individuo un ámbito reservado de su vida frente al conocimiento y la acción de terceros, sean entes públicos 
o simples particulares; que está ligado con el respeto de su dignidad" ${ }^{1}$. Como destacan estos autores, la intimidad entraña el derecho de toda persona a mantener por fuera del conocimiento de los demás ciertos hechos o actuaciones que constituyen la denominada vida privada del individuo ${ }^{2}$.

Sobre el particular VIEGA destaca que "El concepto inicial de intimidad evolucionoi en un sentido positivo, afirmándose la "privacy” como un presupuesto del ejercicio de otros derechos de proyección social e incluso económica. La privacidad es un tema que puede ser enfocado desde múltiples ópticas, desde el cruzamiento de ficheros en soporte papel y de ficheros electrónicos, la privacidad desde la óptica del consumidor y de las telecomunicaciones (sean por cable o inalámbricas) y por supuesto, no podemos dejar de considerar nuestros datos personales en el ámbito de Internet"3.

Esta tuición de la intimidad individual registra antecedentes tanto en el sistema universal, como en el americano de protección de los Derechos Humanos. Así en el artículo 12 de la Declaración Universal de los Derechos Humanos: "Nadie será objeto de injerencias arbitrarias en su vida privada, su familia, su domicilio o su correspondencia, ni de ataques a su honra o a su reputación. Toda persona tiene derecho a la protección de la ley contra tales injerencias o ataques". Por su parte, en el numeral 2 del artículo 11 de Convención Americana sobre Derechos Humanos (Pacto de San José), en sede de protección de la honra y de la dignidad, se señala que "Nadie puede ser objeto de injerencias arbitrarias o abusivas en su vida privada, en la de su familia, en su domicilio o en su correspondencia, ni de ataques ilegales a su honra o reputación".

En el ámbito sanitario, el conocimiento de datos, hechos, actuaciones e incluso secretos de las personas, conjuntamente con la exhibición de determinadas partes de su cuerpo, resulta un requisito ineludible para que se propicie la atención médica. Esta situación hace surgir, según BERRO y ADRIASOLA una confidencialidad "necesaria sobre la vida íntima de la persona enferma, por lo que debe garantizarse la reserva, el secreto médico. La intimidad a pesar de la intromisión de médicos y de otros profesionales del equipo asistencial debe quedar incólume" ". FRANÇA define a dicha regla de confidencialidad como "el derecho de toda persona a proteger los datos que le pertenecen en virtud de que los considera reservados o restringidos (por pertenecer a la intimidad) o su derecho a limitar la difusión de ciertas informaciones u opiniones emitidas" 5 .

ROTONDO, citada por ADRIASOLA y MAGLIA CANZANI, desde una perspectiva bioética, coloca a la privacidad e intimidad dentro de las reglas morales, refiriendo que "Para Kaplan la privacidad no sería una regla derivada de la autonomía, sino un derecho más

1 Cfr. BERRO, Guido y ADRIASOLA, Gabriel. "Confidencialidad" en BERRO, Guido (Coordinador) Medicina Legal. Derecho Médico y aspectos bioéticos, Montevideo, Editorial FCU, 2013, p. 396.

2 Ídem, p. 396.

3 VIEGA, María José. Derecho a la Intimidad en la Sociedad de la información. Ley $N^{\circ}$ 18.331: Impacto $y$ Reglamentacioin. Disponible en http://mjv.viegasociados.com/wp-content/uploads/2011/05/2009Derecho-a-la-intimidad-en-la-sociedad-de-la-informacion.pdf. Fecha de consulta: 21/07/2019.

4 BERRO, Guido y ADRIASOLA, Gabriel, op. cit., p. 396.

5 Cfr. GIL YACOBAZZO, Juan Eduardo y VIEGA RODRÍGUEZ, María José. "Historia clínica electrónica:confidencialidad y privacidad de los datos clínicos" en Revista Médica Uruguaya, Volumen 34, No 4 (2018), p. 229. Disponible en: http://www.rmu.org.uy/revista/proximo/rmu34-4_921-gilhistoria.pdf Fecha de consulta: 21/07/2019. 
básico de una necesidad natural. Por su parte, Stanley Benn establece que las reglas de confidencialidad y privacidad derivan del respeto a la persona: respetar a la persona de modo que sus actividades no puedan ser dañadas por nuestras acciones"

Lo anteriormente expuesto nos lleva en forma inevitable a sostener que la información relativa al estado de salud debe ser categorizada como una especie dentro del género "derecho a la intimidad" y en definitiva como un derecho fundamental. En ese marco es que estimamos, que se logra comprender su verdadera importancia y será útil para el desarrollo que ulteriormente se elucubrará.

A nivel de la normativa vernácula, debemos comenzar por aludir a las regulaciones contenidas por la Ley $\mathrm{N}^{\circ} 18.331$ de 11/08/2008; la que comienza estableciendo, en su artículo $1^{\circ}$, que "El derecho a la protección de datos personales es inherente a la persona humana, por lo que está comprendido en el artículo 72 de la Constitución de la República"; consagrándose en el artículo 11 un principio de reserva, en virtud del cual las personas físicas o jurídicas que obtuvieren legítimamente información proveniente de una base de datos que les brinde tratamiento, están obligadas a utilizarla en forma reservada y exclusivamente para las operaciones habituales de su giro o actividad, estando prohibida toda difusión de la misma a terceros; así como a guardar estricto secreto profesional sobre los mismos (artículo 302 del Código Penal), cuando hayan sido recogidos de fuentes no accesibles al público; excepto en los casos de orden de la Justicia competente o si mediare consentimiento del titular.

Por otra parte, en literal "E" del artículo 4 se califican como "datos sensibles" las informaciones relativas a la salud de las personas. Los efectos que dicha categorización importan, se encuentran explicitados en el artículo 18 de la Ley; destacándose, dentro de otros aspectos, y a los fines del presente trabajo, los siguientes:

1) Que ninguna persona puede ser obligada a proporcionar datos sensibles;

2) Que dichos datos sólo podrán ser objeto de tratamiento con el consentimiento expreso y escrito del titular;

3) Que los datos sensibles sólo pueden ser recolectados y objeto de tratamiento

cuando medien razones de interés general autorizadas por ley, o cuando el organismo solicitante tenga mandato legal para hacerlo. También podrán ser tratados con finalidades estadísticas o científicas cuando se disocien de sus titulares.

Por su parte el artículo 19 establece que "Los establecimientos sanitarios públicos o privados y los profesionales vinculados a las ciencias de la salud pueden recolectar y tratar los datos personales relativos a la salud física o mental de los pacientes que acudan a los mismos o que estén o hubieren estado bajo tratamiento de aquéllos, respetando los principios del secreto profesional, la normativa específica y lo establecido en la presente ley". Dicha previsión debe ser complementada con el Principio de reserva consagrado en el artículo 11, el cual establece que: "Aquellas personas físicas o jurídicas que obtuvieren legitimamente información proveniente de una base de datos que les brinde tratamiento, están obligadas a utilizarla en forma reservada y exclusivamente para las operaciones

6 Cfr. ADRIASOlA, Gabriel y MAGLIA CANZANI, Daniel. "El secreto profesional médico", en RODRÍGUEZ ALMADA, Hugo (Coordinador), Medicina Legal. Derecho Médico, Montevideo, Fundación de Ediciones de la Facultad de Medicina, 2017, p. 167. 
habituales de su giro o actividad, estando prohibida toda difusión de la misma a terceros. Las personas que, por su situación laboral u otra forma de relación con el responsable de una base de datos, tuvieren acceso o intervengan en cualquier fase del tratamiento de datos personales, están obligadas a guardar estricto secreto profesional sobre los mismos (artículo 302 del Código Penal), cuando hayan sido recogidos de fuentes no accesibles al público. Lo previsto no será de aplicación en los casos de orden de la Justicia competente, de acuerdo con las normas vigentes en esta materia o si mediare consentimiento del titular. Esta obligación subsistirá aun después de finalizada la relación con el responsable de la base de datos".

Destaca VIEGA que "No debe confundirse este deber de secreto con el secreto profesional al que están sometidas determinadas personas en función de la profesión que ejercen. Este deber de secreto es un deber genérico que alcanza a cualquier persona que intervenga en el tratamiento de los datos. Sin embargo, la ley uruguaya, en algunos casos lo equipara al secreto profesional, sobre todo a la hora de regular su sanción" .

Debe por último destacarse que el artículo 35 de la Ley, en la redacción dada por los artículos 152 de la Ley $\mathrm{N}^{\circ} 18.719$ de 27/12/2010 y 83 de la Ley $\mathrm{N}^{\circ}$ 19.355 de 19/12/2015, confiere a la Unidad Reguladora y de Control de Datos Personales de la Agencia para el Desarrollo del Gobierno de Gestión Electrónica y la Sociedad de la Información y del Conocimiento (AGESIC) la posibilidad de aplicar sanciones a los responsables de las bases de datos, encargados de tratamiento de datos personales y demás sujetos alcanzados por el régimen legal que infrinjan las obligaciones de reserva anteriormente referenciadas. Dentro de las posibles puniciones se encuentran: a) observación, b) apercibimiento; c) multa de hasta 500.000 UI (quinientas mil unidades indexadas); d) suspensión de la base de datos respectiva por el plazo de cinco días; y e) clausura de la base de datos respectiva (la cual deberá ser promovida ante los órganos jurisdiccionales competentes la clausura).

\subsection{Los datos sanitarios y el secreto profesional médico.}

El secreto profesional es definido por CARRARA como "todo aquello que se confía al profesional en ocasión de su oficio con la intención que no se divulgue". A nivel de la doctrina vernácula BAYARDO BENGOA lo conceptualiza como "la situación que obliga a un profesional a guardar secreto sobre la manifestación de voluntad que ha sido confiada por un particular, en virtud de la relación existente entre ambos" ${ }^{\text {. }}$

ROSSI BAETHGEN refiere a que en el secreto profesional encontramos una serie de elementos o requisitos distintivos, y que pueden ser resumidos de la siguiente forma: a) un elemento personal compuesto por quien comunica y recibe la comunicación, pudiendo ser el receptor del secreto un profesional o una persona que por disposición legal deba mantener el secreto; b) un cometido, que es mantener reserva sobre "ciertos hechos, consideraciones,

7 VIEGA, María José. Los Principios Jurídicos en la Proteccioin de Datos Personales. Anailisis comparativo de la Directiva de la Unioin Europea, la Ley EspanPola y la Ley Uruguaya, p. 21. Disponible en: http://mjv.viegasociados.com/wp-content/uploads/2011/05/Analisis-comparativo-de principios.pdf Fecha de consulta: 21/07/2019.

8 Cfr. ROSSI BAETHGEN, Luis Raúl. "El secreto profesional ante los nuevos desafíos de la libertad y la Responsabilidad" en Revista de Técnica forense, $\mathrm{N}^{\circ} 22$ (2017), p. 121.

9 Cfr. Ídem, p. 121. 
actuaciones humanas en general"; c) un objeto de especial significación para quien lo transmite o a quien se lo adjudica (puede ser un documento, la exteriorización de un sentimiento o de un hecho familiar o societario, etc.); d) una regulación normativa: en nuestro país el fundamento positivo del secreto profesional reside tanto en normas constitucionales (artículos 7, 10, 20, 22, 23, 28 y 332 de la Carta); así como de fuente legal (Código Penal, Código General del Proceso y Código del Proceso Penal) e inclusive algunos Convenios Internacionales suscritos por el país junto con otros estados; y e) un contenido ético, habitualmente destacado en los Códigos de Ética de las diferentes profesiones ${ }^{10}$.

A nivel general, cabe hacer alusión a ciertas normas atinentes a la regulación del secreto profesional. Primeramente, debemos referirnos al artículo 302 del Código Penal que reza: "El que, sin justa causa, revelare secretos que hubieran llegado a su conocimiento, en virtud de su profesión, empleo o comisión, será castigado, cuando el hecho causare perjuicio, con 100 U.R. (cien unidades reajustables) a 600 U.R. (seiscientas unidades reajustables) de multa".

Con respecto al concepto de "justa causa" que habilitaría al profesional a revelar el secreto confiado, ADRIASOLA y MAGLIA CANZANI señalan que doctrinariamente se han distinguido cuatro supuestos en los que cuadraría dicha definición, a saber: 1) el consentimiento del interesado, en tanto el secreto es esencialmente disponible por su titular;2) la situación de necesidad, justificándose la revelación en situaciones excepcionales, para salvar a un tercero de un peligro actual no evitable de otra manera de un daño grave sobre su persona (ejemplo: médico que pone en conocimiento a los parientes del enfermo del peligro de contagio de su enfermedad; 3) cuando el profesional es denunciado o demandado por el cliente o interesado que le confiara el secreto (siendo una especie de legítima defensa); y 4) "la existencia de una norma intrusiva que habilite a una autoridad a ingresar en el secreto (...) Debe existir una norma de rango legal que clara y precisamente le otorgue a un órgano facultades para obligar al depositario del secreto a revelarlo. Si analizado todo el orden jurídico se constata la inexistencia de una norma legal de esa naturaleza el secreto profesional es un secreto no relevable"11; adicionando los autores que, en este último supuesto, sólo una ley dictada por razones de interés general, como lo establece el artículo 28 de la Constitución de la República, puede facultar a un órgano a relevar el secreto profesional $^{12}$.

El Código General del Proceso, en su artículo 156.2 establece que podrán eximirse de su deber de brindar declaración "aquellos que están amparados por el secreto profesional o que por disposición de la ley deban guardar secreto".

Por su parte en el artículo 151 del Código del Proceso Penal aparece una regulación similar a la establecida para el proceso civil, pero más detallada, al prever que: "Deberán abstenerse de declarar quienes deban guardar secreto profesional o mantener información reservada o confidencial. 151.1 Los vinculados por el secreto profesional no podrán ser obligados a declarar sobre lo conocido por razón del ejercicio de su profesión, salvo los casos en que la ley disponga lo contrario. Sin embargo, estas personas no podrán negarse

10 Ibídem, pp. 118-119.

11 ADRIASOLA, Gabriel y MAGLIA CANZANI, Daniel, op. cit., pp. 176-178.

12 Ídem, p. 178. 
a testificar cuando sean liberadas del deber de guardar secreto por quien se los haya confiado. 151.2 Los funcionarios públicos, si conocen de una información clasificada como reservada o confidencial, no estarán obligados a declarar salvo que el juez, a solicitud de parte, considere imprescindible la información. En este caso, el tribunal requerirá la información por escrito e inclusive podrá citar a declarar a los funcionarios públicos que corresponda". Asimismo, en sede de prueba documental, dicho Código, en su artículo 173.4, señala que no serán admisibles "como medio de prueba ni ser utilizadas en modo alguno, las misivas y otras comunicaciones del imputado con su defensor y con personas amparadas por secreto profesional. Esta excepción no rige si dichas personas son también imputadas, ni cuando aquellas son medios para la preparación, ejecución o encubrimiento del delito".

Yendo a las especies del secreto profesional, destaca ROSSI BAETHGEN, que a nivel jurisprudencial se ubica al "secreto profesional de abogados y médicos como casos de reserva que tienen un alcance y un grado de inmunidad elevada diferente a otro tipo de secretos"13; importancia que estimamos se halla vinculada a los caros y altos valores personales en juego cuando se ejercen dichas profesiones.

Especificando en el contexto de este trabajo, Como apuntan ADRIASOLA y MAGLIA CANZANI el secreto médico profesional se remonta a los orígenes de la medicina, en el juramento hipocrático, llegando su desarrollo hasta nuestros días, en los que "sin perder sus rasgos más sobresalientes, ha ido ganando en complejidad como la medicina misma"14.

A su vez, como manifiestan BERRO y ADRIASOLA “La confidencialidad (...) es una de las reglas de la bioética. Toda vez que se establece una relación clínica, el deber de confidencialidad por parte del médico o equipo tratante, opera previamente en la medida en que se entiende un deber nacido con anterioridad al vínculo, de manera que no es necesario agregarlo como una condición más en la relación"15 ; agregando posteriormente que "Todos los códigos de ética, desde la antigüedad, recogen el secreto y su revelación, al menos sin justa causa como contraria a la ética y deontología"16. Esto no es ajeno a la realidad uruguaya, en la que el "Código de Ética Médica”, consagrado en la Ley N 19.286 de 25/09/2014 “Código de Ética Médica”, alude con especificidad y detalle al deber del médico del mantenimiento del secreto de determinadas informaciones de las que tenga conocimiento como derivado del ejercicio de su profesión.

Así, en el literal "e" del artículo 3 se señala que es deber del médico, como profesional de la salud "Respetar el derecho del paciente a guardar el secreto sobre aquellos datos que le pertenecen y ser un fiel custodio, junto con el equipo de salud, de todas las confidencias que se le brindan, las que no podrá revelar sin autorización expresa del paciente".

En el artículo 20 se establece la obligación de los galenos de: “a) Guardar secreto ante terceros de la consulta y de todo aquello que se le haya confiado, incluso después de la muerte del paciente. b) Aceptar asistir a un paciente que no quiere o no puede revelar su identidad en determinadas circunstancias. c) Preservar la confidencialidad de los datos

13 Ibídem, p. 122.

14 ADRIASOLA, Gabriel y MAGLIA CANZANI, Daniel, op. cit., p. 167.

15 BERRO ROVIRA, GUIDO y ADRIASOLA, Gabriel, op. cit., p. 399.

16 Ídem, p. 402. 
revelados por el paciente y asentados en historias clínicas, salvo autorización expresa del paciente. d) Propiciar el respeto a la confidencialidad por parte de todos los trabajadores de la salud. De igual manera, participará en la educación a este respecto. Los registros informatizados deben estar adecuadamente protegidos". Este último literal permite subrayar el carácter de "secreto compartido" al que refieren ADRIASOLA y MAGLIA CANZANI, al explicitar que "En el ámbito de la prestación colectiva de servicios médicos la preservación del secreto profesional médico alcanza no sólo al médico tratante o al equipo médico sino a todo el personal de la institución, sea médico o no médico. El médico, los auxiliares médicos y el personal administrativo de las instituciones, los laboratoristas, los empleados, administrativos, auxiliares de servicio incluso, están obligados a guardar el secreto médico, y si no hacen cometen el delito de revelación del secreto profesional"17.

En el artículo 21 del Código se puntualiza que el secreto profesional debe respetarse aun en la redacción de certificados médicos con carácter de documento público; y que el médico tratante evitará revelar públicamente la patología concreta que aqueje a un paciente, así como las conductas diagnósticas y terapéuticas adoptadas; añadiéndose que "El médico queda liberado de la responsabilidad del secreto solo si el paciente lo consiente explícitamente"; y que deberán ser denunciadas ante Colegio Médico del Uruguay cualquier tipo de presión institucional contraria a lo anteriormente expuesto.

En el artículo 22 se recalca que el respeto a la confidencialidad es un deber inherente a la profesión médica, y que sólo podrá ser relevado "en los casos establecidos por una ley de interés general o cuando exista justa causa de revelación". Sobre el particular, y a vía ejemplificativa, el texto legal considera como justa causa de revelación los siguientes supuestos: a) peligro vital inminente para el paciente (por ejemplo riesgo de suicidio), b) negativa sistemática del paciente de advertir a un tercero acerca de un riesgo grave para la salud de este último (contagio de enfermedades transmisibles, por ejemplo), c) amenaza concreta para la vida de terceros, d) defensa legal contra una acusación de un paciente. Los supuestos referidos en este artículo claramente son estados de necesidad que ingresan en el concepto de justa causa, al que aludiéramos anteriormente.

Finalmente, en el artículo 25 del Código se establece que las reglas de confidencialidad, seguridad y secreto son extensibles a los medios de comunicación sociales.

\section{LAS HISTORIAS CLÍNICAS Y EL ACCESO A LAS MISMAS.}

MAGLIA CANZANI, GAMERO y RODRÍGUEZ ALMADA, señalan que la historia clínica "es un documento o conjunto de documentos generado en la asistencia médica. Sin duda el de mayor relevancia en la práctica clínica y médico-legal" ${ }^{8} ;$ y citando a CRIADO DEL RÍO la definen como "el reflejo de todas las actuaciones médico-sanitarias con el paciente, de toda la relación profesional sanitario-paciente y de todos los conocimientos y actuaciones médicas que se ponen a su disposición"19.

17 ADRIASOLA, Gabriel y MAGLIA CANZANI, Daniel, op. cit., p. 176.

18 MAGLIA CANZANI, Daniel, GAMERO, Sylvia y RODRİGUEZ ALMADA, Hugo. "Documentos médicolegales I. Historia clínica”, en RODRÍGUEZ ALMADA, Hugo (Coordinador), Medicina Legal. Derecho Médico, Montevideo, Fundación de Ediciones de la Facultad de Medicina, 2017, p. 181.

19 Cfr. Ídem, p. 181. 
La eminencia de este documento es puesta de manifiesto por el literal "D” del artículo 18 de la Ley $N^{\circ} 18.335$ de fecha 15/08/2008 sobre "Derechos y Obligaciones de Pacientes y Usuarios de los Servicios de Salud", en la redacción dada por la Ley N²19.670 de 15/10/2018, en el que se señala que todo paciente tiene derecho a que se lleve una historia clínica completa, escrita o electrónica, donde figure la evolución de su estado de salud desde el nacimiento hasta la muerte.

Más adelante el referido artículo asevera que: "La historia clínica es de propiedad del paciente, será reservada y solo podrán acceder a la misma los responsables de la atención médica y el personal administrativo vinculado con estos, el paciente o en su caso la familia y el Ministerio de Salud Pública cuando lo considere pertinente. También podrá ser solicitada directamente al prestador de salud por el Ministerio Público cuando se trate de la historia clínica de una víctima de un delito cuya investigación tenga bajo su dirección, siempre que recabe previamente el consentimiento de aquella o, en su caso de la familia, y a los solos efectos de la acción penal El revelar su contenido, sin que fuere necesario para el tratamiento o mediare orden judicial o conforme con lo dispuesto por el artículo 19 de la presente ley, hará pasible del delito previsto en el artículo 302 del Código Penal" (los destacados son nuestros).

Es dable destacar que la actual redacción del texto legal aludido (por obra de la Ley $\mathrm{N}^{\circ}$ 19.670 de 15/10/2018), es posterior a la entrada en vigencia del Nuevo Código del Proceso Penal.

Dichas previsiones son reafirmadas en la reglamentación del cuerpo legal de marras; específicamente en el artículo 30 del Decreto $N^{\circ}$ 274/010 de 08/09/2010 al establecer que " $L a$ historia clínica será reservada y sólo podrán acceder a la misma: a) Los responsables de la atención a la salud del paciente y el personal administrativo vinculado a dicha atención incluyendo, en las hipótesis a que refiere el literal D del Artículo 51 de la Ley Nro. 18.211, a los del Fondo Nacional de Recursos. b) El paciente o las personas que sean por él autorizadas. c) El representante legal del paciente declaradojudicialmente incapaz. d) En los casos de incapacidad o de manifiesta imposibilidad del paciente, su cónyuge, concubino o el pariente más próximo. e) El Ministerio de Salud Pública incluyendo la Junta Nacional de Salud cuando lo consideren pertinente. Los servicios de salud y los trabajadores de la salud deberán guardar reserva sobre el contenido de la historia clínica y no podrán revelarlo a menos que fuere necesario para el tratamiento del paciente o mediare orden judicial o conforme a lo dispuesto por el Artículo 19 de la Ley $N^{\circ} 18.335$ ”.

A su vez en el artículo 32 del cuerpo reglamentario de marras se regula el ejercicio del derecho de acceso a historias clínicas de personas fallecidas, señalando que el mismo

corresponderá a cualquiera de sus sucesores universales debidamente acreditados. Asimismo, este artículo refiere a que, cuando en la historia clínica existan datos de terceros (excluyéndose los datos del paciente o de las personas vinculadas a la atención de este último) "no podrá ser revelada esta información, a menos que se cuente con el consentimiento de los terceros o que medie orden judicial o requerimiento del Ministerio de Salud Pública".

De acuerdo a la norma citada en el párrafo precedente, se podrán comunicar a terceros datos referidos a la salud del paciente cuando sea necesario por razones de salud e higiene públicas, de emergencia o para la realización de estudios epidemiológicos, en tanto se preserve la identidad de los titulares de los datos mediante mecanismos de disociación adecuados, conforme a lo establecido por la Ley $\mathrm{N}^{\circ} 18.331$. 
Debe también destacarse que en el artículo 15 del Código de Ética Médica se hace referencia a que la historia clínica es un documento fundamental en el acto médico, de ahí que el médico tiene el deber y el derecho de registrar el acto médico en una historia clínica, que pertenece al paciente pero que quedará bajo la custodia del médico tratante o de la institución de la que es usuario.

El desarrollo antecedente permite caracterizar a la historia clínica como documentación "confidencial", abarcada por el secreto profesional; y que por tanto amerita se desarrollen los mecanismos de protección respectiva por parte de sus custodios. Como refiere ADRIASOLA, "la no protección de los datos asentados en la historia clínica constituiría una forma oblicua de violación del secreto profesional" ${ }^{20}$. Sobre el particular MAGLIA CANZANI, GAMERO y RODRÍGUEZ ALMADA estiman que una forma de impedirle a alguien ejercer el derecho y deber de cuidar de su salud consagrado en el artículo 44 de la Constitución de la República, sería "no garantizarle la confidencialidad de los datos que imprescindiblemente debe aportar para el tratamiento de su problema de salud y que necesariamente debe registrarse en su historia clínica. Si se quebrantara ese deber de secreto y los datos aportados tomaran estado público, podrían ir en contra del propio paciente, lo cual lo discrimina y le restringe el derecho a la asistencia" ${ }^{21}$.

Puntualiza ADRIASOLA que ninguna de las normas anteriormente aludidas son intrusivas en la esfera de la intimidad, y por tanto tampoco habilitan a la Justicia a relevar del secreto profesional del que están munidas las historias clínicas; ni siquiera el literal "D" del artículo 18 de la Ley $\mathrm{N}^{\circ} 18.335^{22}$. Este autor entiende que para que "una norma que autorice a la justicia penal a relevar el secreto profesional médico y en consecuencia violar el derecho a la intimidad del paciente contenido en la historia clínica debe observar los siguientes requisitos: a) determinación del fuero judicial autorizado legalmente a violar la intimidad; b) determinación de la naturaleza del proceso en que puede emitir ese mandato; c) exigencia de motivación. Y es que la autorización para que una autoridad publica viole la intimidad de los ciudadanos debe estar estrictamente reguladay delineada desde que se trata de una "restricción de derechos fundamentales" ${ }^{23}$; conforme al texto constitucional. ADRIASOLA explaya que el articulo 18 de la Ley $\mathrm{N}^{\circ} 18.335$ no es una norma intrusiva en la esfera de la intimidad, que importe que la historia clínica es ahora permeable a cualquier mandato judicial, ya que "No define cual es la "justicia competente", no define en queì procedimientos y bajo que circunstancias puede el juez violar la intimidad del ciudadano-paciente" 24 ; agregando este teórico que "En esas circunstancias, el centro sanitario tiene el deber de verificar si la orden judicial cuenta con el consentimiento del paciente y titular del secreto. Y si constata que ello no es asî̀, debe negarse a cumplir el mandato de la justicia"25.

20 Cfr. MAGLIA CANZANI, Daniel, GAMERO, Sylvia y RODRÍGUEZ ALMADA, Hugo, op. cit., p. 188. 21 Ídem, p. 188.

22 ADRIASOLA, Gabriel. Solicitudes o allanamientos para secuestrar historias cliìnicas. La cliinica meidica como "domicilio especial". Disponible en: http://www.medicinalegal.edu.uy/bibliografia/ archivos/la_clinica_medica_como_domicilio_especial.pdf

Fecha de consulta: 21/07/2019, p. 3.

23 Ídem, pp. 3-4.

24 Ibídem, p. 6.

25 Ibídem, p. 6. 
Humildemente no tenemos el honor de compartir la opinión de este distinguido profesor en este punto. Sobre el particular estimamos que el supuesto prevenido en el artículo 18 de la Ley $\mathrm{N}^{0} 18.335$ al referir a "orden judicial" se está aludiendo a uno de los supuestos excepcionales en los que se puede relevar del secreto profesional del que están dotadas las historias clínicas, dado que, por una Ley, dictada en razón del interés general se acepta la restricción de un derecho que indudablemente es fundamental, lo que se encuentra en consonancia con lo prevenido por el artículo 7 de la Constitución de la República. Nótese además que, como el propio ADRIASOLA sostiene, "el oirgano que la ley debe autorizar para tomar la decisioin de la intrusioìn debe ser necesariamente un juez. Ello debido a que de acuerdo al artiiculo 23 de la Constitucioin de la Repuiblica los jueces son los custodios de las garantiias individuales. En un Estado Democraitico de Derecho, toda intromisioin en la intimidad como fuente de prueba en un proceso penal debe necesariamente ser ordenada por un tribunal" 26 ; y en ese sentido la norma también resulta ajustada al texto constitucional.

\section{LAS POSIBILIDADES DE ACCESO A DATOS SANITARIOS DE PERSONAS EN EL MARCO DE INVESTIGACIONES CRIMINALES POR PARTE DE FISCALES.}

\subsection{Algunas previsiones de interés en materia probatoria del nuevo Código del Proceso Penal.}

Sin perjuicio de las reseñadas atribuciones que detenta el Fiscal en virtud del artículo 45 del Código del Proceso Penal para conducir la investigación, existen ciertas restricciones que ciñen su accionar.

Como expusiéramos pretéritamente, en el artículo 151 del cuerpo normativo aprobado por la Ley $\mathrm{N}^{\circ} 19.293$, se establece una limitante en materia de prueba testimonial, al señalar que deberán abstenerse de prestar declaración quienes deban guardar secreto profesional o mantener información reservada o confidencial; no pudiendo ser obligados salvo los casos en que la ley disponga lo contrario. Sin embargo, estas personas no podrán negarse a testificar cuando sean liberadas del deber de guardar secreto por quien se los haya confiado.

Dicho artículo, establece en su numeral 2, que los funcionarios públicos, si conocen de una información clasificada como reservada o confidencial, no estarán obligados a declarar salvo que el juez, a solicitud de parte, considere imprescindible la información. En este caso, el tribunal requerirá la información por escrito e inclusive podrá citar a declarar a los funcionarios públicos que corresponda.

Los puntos referidos en los dos párrafos anteriores deberán ser tenidos especialmente en consideración por los integrantes de los equipos asistenciales que sean citados en el marco de una investigación criminal a las oficinas de una fiscalía a efectos de brindar declaración testimonial sobre el estado de salud de un paciente. A nuestro juicio, la consecuencia elemental de dichas disposiciones deriva en que dichos testigos deberán negarse a declarar sobre aspectos relativos a información sanitaria de personas a las que hayan asistido, salvo que estas últimas los liberen de su obligación de secreto.

26 Ibídem, p. 4. 
Por otra parte, en sede de prueba documental, dicho Código, en su artículo 173.1 establece que: "Se podrá incorporar al proceso todo documento que pueda servir como medio de prueba. Quien lo tenga en su poder está obligado a presentarlo, exhibirlo o permitir su conocimiento, salvo dispensa o prohibición legal o necesidad de previa orden judicial"; circunstancia que denota que existen documentos que para cuya agregación el fiscal por sí mismo no podría diligenciar, o bien porque existe un impedimento de índole legal o bien se requiere una orden del juez competente. A su vez, en el artículo 173.4, se señala que no serán admisibles "como medio de prueba ni ser utilizadas en modo alguno, las misivas y otras comunicaciones del imputado con su defensor y con personas amparadas por secreto profesional. Esta excepción no rige si dichas personas son también imputadas, ni cuando aquellas son medios para la preparación, ejecución o encubrimiento del delito". En este caso, estimamos que la previsión resulta aplicable a la documentación contenida en las historias clínicas, en tanto resulta amparada por el secreto profesional.

Debe acotarse que en sede de levantamiento de secreto bancario y reserva tributaria; los artículos 211 y 212 del Código establecen que para que se proceda al mismo se requiere solicitud del fiscal, dirigida al tribunal, siendo este último el que por resolución fundada podrá disponerlo. Este punto no es menor a los efectos de la analogía; en tanto, los secretos bancario y tributario son, en definitiva, especies del género secreto profesional; y en definitiva queda de manifiesto que no se ha conferido a los integrantes del Ministerio Público la potestad de poder relevar secreto profesional en ningún caso.

\section{2. ¿Cuáles son las perspectivas de acceso a datos sanitarios por parte de Fiscales?}

En función de la normativa analizada, las posibilidades de acceso de los Fiscales a información referente al estado de salud de una persona, durante el decurso de una investigación criminal se encuentran acotadas a los siguientes supuestos:

A) Si lo que se requiere es la agregación de la historia clínica de un determinado usuario de una institución asistencial, solo podrá requerirlo a esta última, si dicha persona es víctima de un delito y siempre que se recabe previamente el consentimiento de aquella o, en su caso de la familia (el cual estimamos, deberá ser expreso y encontrarse adjuntado a la solicitud), y a los solos efectos de la acción penal (literal "D" del artículo 18 de la Ley $\mathrm{N}^{\circ}$ 18.335). Entendemos que en caso de imposibilidad manifiesta del titular de la historia clínica a brindar su consentimiento, los familiares legitimados a otorgar el mismo serían su cónyuge, concubino o el pariente más próximo, por remisión al artículo 30 del Decreto $\mathrm{N}^{\circ}$ 274/010; y en el caso fallecidos correspondería los sucesores debidamente acreditados conforme al artículo 32 del precitado cuerpo reglamentario.

B) Si los datos e información sobre el estado sanitario de una persona pretenden ser recabados por la vía de declaraciones testimoniales tomadas al personal médico y no médico que participó en la asistencia de la misma; tales testigos deberán abstenerse a declarar, salvo que sean liberados de su obligación de mantener el secreto profesional por parte del titular de dicha información, es decir el paciente.

Fuera de los casos señalados, no corresponderá proporcionar acceso a los Fiscales a este tipo de información. Quienes lo hagan o faciliten tal acceso, se expondrán a tipificar el delito consagrado en el artículo 302 del Código Penal. Asimismo, las instituciones podrían sufrir las puniciones administrativas consagradas en el artículo 35 de la Ley $\mathrm{N}^{\circ} 18.331$. 


\section{Conclusiones.}

La información relativa al estado de salud de las personas se enmarca dentro de la protección al derecho a la intimidad de los seres humanos; el cual, notoriamente pertenece al elenco de los derechos fundamentales, consagrados en sendos artículos dde la Constitución de la República e instrumentos internacionales, universales y regionales en materia Derechos Humanos. Este aspecto no es una mera abstracción o remisión genérica, sino que es el cimiento básico en el que se sustentan las significativas rémoras legales, mayoritariamente insalvables, para quien pretenda hacerse con este tipo de datos sin contar con las debidas autorizaciones o atribuciones, sean éstas conferidas por el titular del derecho o excepcionalmente por textos positivos.

Sobre las bases reseñadas, el Ordenamiento Jurídico ha creado determinados mecanismos que acentúan el tenor de la tuición de la privacidad en materia sanitaria, siendo uno de los más destacables el secreto profesional, el cual no solamente alcanza al médico tratante del paciente, sino a todo el personal asistencial y no asistencial de la institución sanitaria. La infracción a tales preceptos conlleva responsabilidades en sedes penal y administrativa; por lo que tantos los profesionales e instituciones que potencialmente pudieran verse afectados por dichas situaciones, deberán ser especialmente celosos en el cuidado de la reserva tanto de los documentos médico-legales, como de la no difusión de datos emanados de estos últimos o de los procedimientos asistenciales llevados en sus pacientes.

Son estas circunstancias las que primeramente obstaculizan a los Fiscales, durante el desarrollo de investigaciones penales, a acceder a información sanitaria, sea por la vía de declaraciones testimoniales, o por la de solicitud de remisión de historias clínicas, siempre que no se cuente con el consentimiento debido del titular de tal información.

La obtención de tales datos por fuera de los supuestos habilitados por las normas sustanciales referidas en este trabajo, importaría, a nuestrojuicio, su inadmisibilidad como medio probatorio, conforme a las reglas del propio Código del Proceso Penal, en tanto son atinentes a la esfera de derechos personalísimos y fundamentales, cuya invasión le está vedada a los integrantes del Ministerio Público, conforme a las disposiciones vernáculas vigentes. En tal sentido el cuerpo normativo mencionado prevé supuestos en los que, para que el fiscal pueda ingresar en la esfera de la intimidad de la persona, sin el consentimiento de la misma, debe necesariamente solicitar la autorización judicial pertinente (secreto tributario, secreto bancario, etc.); lo que resulta perfectamente trasladable

Como cierre y corolario de lo de lo anteriormente expuesto, quisiéramos destacar que, la lógica de nuestro sistema jurídico determina que, al amparo de la Ley (dictada en razones de interés general) sean los jueces y no los fiscales, quienes puedan restringir el goce de ciertos derechos fundamentales. Sobre el particular debe recordarse, como fuera sostenido ut-supra, que, en un Estado de Derecho, los magistrados son considerados la salvaguarda de las garantías individuales; circunstancia que, a nuestro criterio, presumiblemente deriva de su rol imparcial en las contiendas subjetivas que le son presentadas para su dilucidación. Dicho papel no le cabe al Fiscal; el cual, sin perjuicio de desarrollar también una encomiable función de vital importancia en el sistema de justicia, no deja de tener una mirada parcial o interesada dentro de los procesos penales; ya que, como reza el artículo 45.2 del Código del Proceso Penal: "Cuando el Ministerio Público ejerce la acción penal, es parte en el proceso". 


\section{BIBLIOGRAFÍA CONSULTADA}

ADRIASOLA, Gabriel y MAGLIA CANZANI, Daniel. "El secreto profesional médico", en RODRÍGUEZ ALMADA, Hugo (Coordinador), Medicina Legal. Derecho Médico, Montevideo, Fundación de Ediciones de la Facultad de Medicina, 2017.

ADRIASOLA, Gabriel. Solicitudes o allanamientos para secuestrar historias cliinicas. La cliìnica meidica como "domicilio especial". Disponible en http://www.medicinalegal .edu.uy/bibliografia/archivos/la_clinica_medica_como_domicilio_especial.pdfFecha de consulta: 21/07/2019.

BERRO, Guido y ADRIASOLA, Gabriel. "Confidencialidad” en BERRO, Guido (Coordinador) Medicina Legal. Derecho Médico y aspectos bioéticos, Montevideo, Editorial FCU, 2013.

GIL YACOBAZZO, Juan Eduardo y VIEGA RODRÍGUEZ, María José. "Historia clínica electrónica: confidencialidad y privacidad de los datos clínicos" en Revista Médica Uruguaya, Volumen 34, $\mathrm{N}^{\circ} 4$ (2018). Disponible en http://www.rmu.org.uy/revista/ proximo/rmu34-4_921-gil-historia.pdf Fecha de consulta:21/07/2019.

MAGLIA CANZANI, Daniel, GAMERO, Sylvia y RODRÍGUEZ ALMADA, Hugo. "Documentos médico-legales I. Historia clínica", en RODRÍGUEZ ALMADA, Hugo (Coordinador), Medicina Legal. Derecho Médico, Montevideo, Fundación de Ediciones de la Facultad de Medicina, 2017.

ROSSI BAETHGEN, Luis Raúl. "El secreto profesional ante los nuevos desafíos de la libertad y la Responsabilidad" en Revista de Técnica forense, NN$^{\circ} 22$ (2017).

VIEGA, María José. Derecho a la Intimidad en la Sociedad de la información. Ley $N^{o}$ 18.331: Impacto y Reglamentacioin. Disponible en http://mjv.viegasociados.com/wpcontent/uploads/2011/05/2009-Derecho-a-la-intimidad-en-la-sociedad-de-lainformacion.pdf Fecha de consulta: 21/07/2019.

VIEGA, María José. Los Principios Juridicos en la Proteccioìn de Datos Personales. Anailisis comparativo de la Directiva de la Unioìn Europea, la Ley EspanFola y la Ley Uruguaya, p. 21. Disponible en http://mjv.viegasociados.com/wp-content/uploads/ 2011/05/Analisis-comparativo-de principios.pdf Fecha de consulta:21/07/2019.

Fecha de recepción: 20 junio 2019.

Fecha de aceptación: 19 julio 2019. 